\title{
Chlamydia trachomatis and placental inflammation in early preterm delivery
}

\author{
G. Ingrid J. G. Rours • Ronald R. de Krijger • Alewijn Ott • \\ Hendrina F. M. Willemse • Ronald de Groot • Luc J. I. Zimmermann • \\ Renee F. Kornelisse $\cdot$ Henri A. Verbrugh $\cdot$ Roel P. Verkooijen
}

Received: 14 April 2010/Accepted: 9 March 2011/Published online: 24 March 2011

(C) The Author(s) 2011. This article is published with open access at Springerlink.com

\begin{abstract}
Chlamydia trachomatis may infect the placenta and subsequently lead to preterm delivery. Our aim was to evaluate the relationship between the presence of Chlamydia trachomatis and signs of placental inflammation in women who delivered at 32 weeks gestation or less. Setting: placental histology and clinical data were prospectively obtained from 304 women and newborns at the Erasmus MC-Sophia, Rotterdam, the Netherlands. C. trachomatis testing of placentas was done retrospectively using PCR. C. trachomatis was detected in $76(25 \%)$
\end{abstract}

\section{G. I. J. G. Rours $(\bowtie)$}

Department of Paediatric Infectious Disease and Immunology,

Erasmus MC, Dr. Molewaterplein 60, 3015 GJ Rotterdam,

The Netherlands

e-mail: Rours@mac.com

G. I. J. G. Rours · H. F. M. Willemse - H. A. Verbrugh ·

R. P. Verkooijen

Department of Medical Microbiology and Infectious Diseases,

Erasmus MC, Rotterdam, The Netherlands

R. R. de Krijger

Department of Pathology, Josephine Nefkens Institute,

Erasmus MC, Rotterdam, The Netherlands

A. Ott

Laboratory for Infectious Diseases, Groningen, The Netherlands

R. de Groot

Department of Pediatrics, UMC St Radboud, Nijmegen,

The Netherlands

\section{J. I. Zimmermann}

Department of Paediatrics, Maastricht University Hospital,

Maastricht, The Netherlands

R. F. Kornelisse

Department of Paediatrics, Erasmus MC, Rotterdam,

The Netherlands placentas. Histological evidence of placental inflammation was present in 123 (40\%) placentas: in 41/76 (54\%) placentas with $C$. trachomatis versus $82 / 228$ (36\%) placentas without $C$. trachomatis infection (OR 2.1, 95\% CI 1.2-3.5). $C$. trachomatis infection correlated with the progression $(P=0.009)$ and intensity $(P=0.007)$ of materno-fetal placental inflammation. $C$. trachomatis DNA was frequently detected in the placenta of women with early preterm delivery, and was associated with histopathological signs of placental inflammation.

Keywords Chlamydia trachomatis - Placental inflammation · Pregnancy $\cdot$ Prematurity

\section{Introduction}

Preterm birth is the main cause of perinatal morbidity and mortality worldwide accounting for $60-80 \%$ of deaths of infants born without congenital abnormalities [1]. Preterm labor is associated with placental inflammation, especially with acute chorioamnionitis [2,3]. Many studies associated clinical and histological chorioamnionitis with acute neonatal morbidity and mortality and, at least to some degree, also with neurological impairments and chronic lung disease [4-8].

Chlamydia trachomatis is the most common bacterial sexually transmitted infection worldwide, including in the Netherlands [9]. Starting as cervicitis, chlamydial infection may ascend and infect the placenta or amniotic fluid, which may subsequently lead to preterm delivery. The literature regarding the association of maternal $C$. trachomatis infection with preterm delivery, however, is conflicting due to differences in study design, population and microbiological test methods [10-24]. 
The aims of this study were to detect $C$. trachomatis infection in placentas of women with early preterm delivery and to associate $C$. trachomatis infection with histological signs of placental inflammation. The literature is very limited regarding this association, but may be relevant to explain a component causal effect of $C$. trachomatis infection on preterm delivery. In addition, we studied the association of $C$. trachomatis infection with delivery characteristics and neonatal outcome in this selected cohort of women.

\section{Methods}

\section{Patients and design}

The chorioamnionitis study, during which the placentas were collected that we used in the current Chlamydia trachomatis study, was prospective, observational, and noninterventional. Pregnant women, who delivered live newborns between May 2001 and February 2003 at the Erasmus MC-Sophia, Rotterdam, the Netherlands, at a gestational age of 32 weeks or less, were eligible for the study. Regular health care workers (residents, research-nursing staff, neonatologists) informed the women about the study. Enrolment took place immediately after delivery when the newborns were admitted to the neonatal intensive care unit. Women were excluded from the study if the placenta was not available for histological examination and, at a later stage, if no more placental tissue was available to test for $C$. trachomatis. Antenatal, perinatal and neonatal data were obtained from maternal and neonatal medical records and prospectively stored in a database. Follow up of neonates was until a postnatal age of 28 days or postmenstrual age of 36 weeks. Neonates, who were transferred to another hospital, were followed in order to complete the data. Placentas were examined for evidence of infection or other pathology. Retrospectively, the placentas were examined for the presence of $C$. trachomatis.

Maternal ethnicity was self-classified in this study. In total 32 different nationalities were registered. Most women were Dutch $(70 \%)$, Turkish (7\%), Surinamese $(4 \%)$ or Moroccan (3\%). Nationalities were clustered in six ethnic groups: Central European, Eastern European, Mediterranean, Caribbean/South-American, Azian and African. We used the following definitions. Clinical signs of chorioamnionitis were recorded and defined by the presence of two or more of the following signs: abdominal pain, cervical discharge, leucocytosis (white blood cell count $\geq 15 \times 10^{9} / 1$ ), fever (maternal temperature $>38^{\circ} \mathrm{C}$ ), and raised CRP (C-reactive protein $\geq 15 \mu / \mathrm{L}$ ). Pre-eclampsia was defined as new-onset hypertension (blood pressure $>140 / 90 \mathrm{mmHg}$ ) with proteinuria [25]. Fetal distress was considered present when indicated by the obstetrician based on cardiotocographic criteria. Gestational age was estimated by ultrasonography or by using the last menstrual period when reliable. Small for gestational age (SGA): birth weight less than two standard deviations of the mean for gestational age. Respiratory distress syndrome (RDS) was defined according to Giedeon [26]. Broncho-pulmonary dysplasia (BPD): dependency on oxygen supplementation at a postmenstrual age of 36 weeks. Intraventricular haemorrhage (IVH) and periventricular leucomalacia (PVL) were defined according to Volpe [27]. Necrotising enterocolitis (NEC) was defined as stage two or higher according to Bell [28].

\section{Histopathology}

Immediately after delivery placentas and membranes were fixed in formalin for at least $16 \mathrm{~h}$. Sampling was performed according to a standard protocol with two membrane rolls, two cross sections of the cord and three representative blocks of the placental disk as a minimum. The tissues were thereafter, according to routine standard methodology for pathological specimens, embedded in paraffin until histopathological examination. To prevent inter-examiner variation, the same pathologist who was specialized in perinatal pathology examined all placentas for histological evidence of inflammation. The pathologist was blinded to clinical information. Placental inflammation was categorized according to a maternal inflammatory response (MIR) and fetal inflammatory response (FIR) as suggested by the Amniotic Fluid Infection Nosology Committee [29], and was considered positive if there was any evidence of a MIR and/or FIR. The MIR was divided into three stages (acute subchorionitis or chorionitis, acute chorioamnionitis, necrotizing chorioamnionitis) representing progression of disease, and two grades representing intensity of disease; the FIR was similarly divided into three stages (chorionic vasculitis or umbilical phlebitis, umbilical vasculitis or umbilical panvasculitis, (subacute) necrotizing funisitis or concentric umbilical perivasculitis) and two grades [29].

After histopathological examination, the placentas were stored in paraffin blocks at room temperature. Before testing for $C$. trachomatis, the paraffin blocks were cut on different days using the same microtome with single use disposable blades. Care was taken to clean materials between cases to avoid contamination. The paraffin blocks were cut until the surface was straight after which five samples per paraffin block each of $10 \mu \mathrm{m}$ thickness were cut for further microbiological analysis.

\section{Microbiology}

For DNA Isolation, tissue samples were deparaffinized with xylene at room temperature and washed in ethanol. 
Bacterial DNA was isolated using the QIA Amp Tissue Kit (QIAgen, Hilden, Germany). After a first lysis with proteinase K, DNA was bound to a QIAamp spin column, the column washed twice, the purified DNA eluded from the column in an elution buffer $\mathrm{AE}$, and preheated at $70^{\circ} \mathrm{C}$.

For DNA amplification and detection, a Real-time PCR was carried out using the Lightcycler 2.0 system and FastStart DNA Master SYBR Green I kit (Roche Diagnostics, Almere, The Netherlands). Each PCR reaction contained $3 \mathrm{mM} \mathrm{MgCl} 2$ and $0.5 \mu \mathrm{M}$ of each of the two primers NLO 5'-ATGAAAAAACTCTIGAAATCG-3' (position 1-21) and NRO 5'-CTAACTGTAACTGCGTATTT-3' (position 1128-1108) to amplify C. trachomatis plasmid DNA [30], was denatured for $10 \mathrm{~min}$ at $95^{\circ} \mathrm{C}$, subjected to 40 cycles of $15 \mathrm{~s}$ at $95^{\circ} \mathrm{C}, 10 \mathrm{~s}$ at $60^{\circ} \mathrm{C}$ and $20 \mathrm{~s}$ at $72^{\circ} \mathrm{C}$. To check the specificity of amplification products, a melting curve analysis was performed consisting of heating from 65 to $95^{\circ} \mathrm{C}$ at a rate of $0.1 \mathrm{~s}$ per step and holding for $20 \mathrm{~s}$ at each step for data acquisition. The melting temperature for the specific amplicons was $82^{\circ} \mathrm{C}$. For each sample, the PCR was done using a separate internal validation ( $\beta$-globine PCR). For each run a negative control (water) and three positive controls (dilutions of purified $C$. trachomatis) were included.

\section{Ethical aspects}

The study was approved by the Medical Ethics Committee for Research on Human Subjects of the Erasmus MC, Rotterdam, the Netherlands.

\section{Statistical analysis}

Statistical analysis was performed using the Statistical Package of Social Sciences version 11.0 for Windows (SPSS Inc. Chicago, Illinois, USA). Since pre-eclampsia and chorioamnionitis are two distinct potential pathways to preterm delivery, stratified analysis was done regarding the differences in maternal morbidity. For comparison of categorical variables between groups the Pearson's Chi-square test or Fisher's Exact test was used. For comparison of continuous variables the two-tailed Student's T-test was used. The Mantel-Haenszel test was used to asses trends. Statistical significance was considered $P<0.05$.

\section{Results}

Three hundred and twenty-three pregnant women were eligible for the study. Placental tissue and clinical data were available for 304 (94\%) women and their newborns.
C. trachomatis in relation to clinical characteristics

C. trachomatis was detected by PCR in placental tissue of $76 / 304$ (25\%) women. One woman had a record of C. trachomatis infection prior to the current pregnancy. Three women were tested and found to be positive during the current pregnancy. None of these women had $C$. trachomatis detected in their placenta. Eighty-four women received antibiotics for PPROM or signs of infection. Chlamydia-positive women received more often antibiotics than chlamydia-negative women: 32/76 (42\%) versus 52/228 (23\%); (OR 2.5, 95\% CI 1.4-4.4), and received more often erythromycin: 14 (18\%) versus 20 (9\%); (OR 2.4, 95\% CI 1.1-5.2). Amoxicillin-clavulanic acid and amoxicillin were prescribed more often to chlamydiapositive women, but did not differ significantly between the two groups: 19 (25\%) versus 36 (16\%); (OR 1.8; $95 \% \mathrm{CI}$ 0.9-3.3).

Antenatal, clinical and delivery characteristics of women with and without $C$. trachomatis infection are compared in Table 1. Maternal age, parity, and gravidity were similar for women in both groups and the distribution of chlamydial detection was homogenous among ethnic groups $(P=0.8)$. Presence of two or more clinical signs of chorioamnionitis was not significantly more often observed among chlamydia-positive women than among chlamydianegative women. PROM did not differ between the two groups. Chlamydia-positive women had significantly less often pre-eclampsia $(P=0.002)$ and delivered significantly less often after fetal distress $(P=0.03)$ and by caesarean section $(P=0.002)$ than chlamydia-negative women, and their newborns were significantly less often small for their gestational age $(P=0.02)$. Neonatal outcomes such as RDS, BPD, IVH, PVL, and neonatal mortality rate were not significantly different between neonates born to chlamydia-positive and chlamydia-negative women (data not shown).

Since the above-mentioned differences could be due to the differences in maternal morbidity (women without and with pre-eclampsia), a stratified analysis was performed as shown in Table 2. After stratification, the differences between chlamydia-positive and chlamydia-negative women became non-significant. Among the women with pre-eclampsia, neonates born to chlamydia-positive women were less often small for gestational age than those born to chlamydia-negative women $(P=0.02)$. Neonatal outcomes as BPD, IVH, PVL and neonatal mortality rate were not significantly different between strata (data not shown), but RDS grade I-II was observed more often in neonates born to $9 / 17(53 \%)$ chlamydia-positive women with preeclampsia than in 25/96 (26\%) chlamydia-negative women with pre-eclampsia (OR 3.2; 95\% CI 1.1-9.2; $P=0.03$ ). 
Table 1 Clinical characteristics of pregnancies according to Chlamydia trachomatis status

Numbers are mean \pm SD or number (\%), $n$ number, $O R$ odds ratio, $C I$ confidence interval, $N A$ not applicable, $C A$ chorioamnionitis, PROM premature rupture of membranes

Table 2 Clinical characteristics according to Chlamydia trachomatis status by strata of pre-eclampsia

Numbers are mean \pm SD or number $(\%), n$ number, $O R$ odds ratio, $C I$ confidence interval, $N A$ not applicable, $C A$

chorioamnionitis, PROM premature rupture of membranes, $S G A$ small for gestational age. Analysis with Pearson's Chi-square test or Fisher's Exact test; * $\mathrm{P}=0.02$
C. trachomatis negative

C. trachomatis positive

OR $(95 \% \mathrm{CI})$

$(n=228)$

$(n=76)$

Antenatal characteristics

$\begin{array}{llll}\text { Maternal age } & 30.9 \pm 5.3 & 30.1 \pm 5.0 & \text { NA } \\ \text { Para } & 1.8 \pm 1.3 & 1.9 \pm 1.1 & \text { NA } \\ \text { Gravida } & 2.2 \pm 1.7 & 2.0 \pm 1.2 & \text { NA } \\ \text { Clinical characteristics } & & & \\ \geq 2 \text { clinical signs CA } & 48(21) & 24(32) & 1.7(0.97-3.1) \\ \text { Fetal distress } & 114(50) & 27(36) & 0.6(0.3-1.0) \\ \text { PROM } & 63(28) & 24(32) & 1.3(0.7-2.2) \\ \text { Pre-eclampsia } & 96(42) & 17(22) & 0.4(0.2-0.7) \\ \text { Delivery characteristics } & & & 0.4(0.3-0.8) \\ \text { Caesarean section } & 146(64) & 33(43) & \text { NA } \\ \text { Gestational age } & 29.1 \pm 1.9 & 29.1 \pm 1.9 & \text { NA } \\ \text { Birth weight (gram) } & 1,124 \pm 347 & 1,207 \pm 350 & 0.5(0.2-0.9) \\ \text { Small for gestational age } & 67(29) & 12(16) & \end{array}$

\begin{tabular}{|c|c|c|c|}
\hline No pre-eclampsia & $\begin{array}{l}\text { C. trachomatis negative } \\
n=132 \text { (69) }\end{array}$ & $\begin{array}{l}\text { C. trachomatis positive } \\
n=59 \text { ( } 31)\end{array}$ & OR $(95 \% \mathrm{CI})$ \\
\hline \multicolumn{4}{|l|}{ Antenatal characteristics } \\
\hline Maternal age & $30.8 \pm 5.1$ & $30.1 \pm 4.8$ & NA \\
\hline Para & $1.9 \pm 1.3$ & $1.9 \pm 1.1$ & NA \\
\hline Gravida & $2.3 \pm 1.7$ & $2.0 \pm 1.2$ & NA \\
\hline \multicolumn{4}{|l|}{ Clinical characteristics } \\
\hline$\geq 2$ clinical signs $\mathrm{CA}$ & $47(36)$ & $24(41)$ & $1.2(0.7-2.3)$ \\
\hline Fetal distress & $41(31)$ & $16(27)$ & $0.8(0.4-1.6)$ \\
\hline PROM & $60(45)$ & $24(41)$ & $0.8(0.4-1.5)$ \\
\hline \multicolumn{4}{|l|}{ Delivery characteristics } \\
\hline Caesarean section & $59(45)$ & $20(34)$ & $0.6(0.3-1.2)$ \\
\hline Gestational age & $28.8 \pm 2.0$ & $29.1 \pm 2.0$ & NA \\
\hline Birth weight (gram) & $1,194 \pm 354$ & $1,223 \pm 359$ & NA \\
\hline SGA & $18(14)$ & $9(15)$ & $1.1(0.5-2.7)$ \\
\hline Pre-eclampsia & $\mathrm{n}=96(85)$ & $\mathrm{n}=17(15)$ & \\
\hline \multicolumn{4}{|l|}{ Antenatal characteristics } \\
\hline Maternal age & $31.1 \pm 5.6$ & $30.0 \pm 5.7$ & NA \\
\hline Para & $1.7 \pm 1.2$ & $1.8 \pm 1.1$ & NA \\
\hline Gravida & $2.0 \pm 1.7$ & $1.9 \pm 1.2$ & NA \\
\hline \multicolumn{4}{|l|}{ Clinical characteristics } \\
\hline$\geq 2$ clinical signs $\mathrm{CA}$ & $1(1)$ & $0(0)$ & NA \\
\hline Fetal distress & $73(76)$ & $11(65)$ & $0.6(0.2-1.7)$ \\
\hline PROM & $3(3)$ & $1(6)$ & $1.9(0.2-19.8)$ \\
\hline \multicolumn{4}{|l|}{ Delivery characteristics } \\
\hline Caesarean section & $87(91)$ & $13(77)$ & $0.3(0.1-1.3)$ \\
\hline Gestational age & $29.5 \pm 1.7$ & $29.1 \pm 1.8$ & \\
\hline Birth weight (gram) & $1,027 \pm 314$ & $1,151 \pm 321$ & \\
\hline SGA* & $49(51)$ & $3(18)$ & $0.2(0.06-0.7)$ \\
\hline
\end{tabular}


C. trachomatis in relation to histological signs of placental inflammation

Histological evidence of placental inflammation was present in 123/304 (40\%) women of whom $64(52 \%)$ had inflammation diagnosed in both maternal and fetal tissue, $50(41 \%)$ in maternal tissue only, and four $(3 \%)$ in fetal tissue only. Five (4\%) placentas showed other specific features including peripheral funisitis, acute villitis, acute intervillositis with intervillous abscesses, or the presence of decidual plasma cells, but had no signs of a maternal or fetal inflammatory response. Chlamydia-positive women had significantly more often histopathological signs of placental inflammation than chlamydia-negative women: 41/76 (54\%) versus 82/228 (36\%); (OR 2.1, 95\% CI 1.2-3.5).

The progression and intensity of inflammation of maternal tissue only and the combination of maternal and fetal tissues were assessed in relation to $C$. trachomatis infection (Table 3). For the latter combination, the highest stage or grade of inflammation in either maternal or neonatal tissue was assessed in trend analysis. Chlamydiapositive women had significantly more often signs of inflammation in both maternal and fetal tissue for progression stage 3 and intensity grade 2 in their placentas than chlamydia-negative women. In addition, a significantly increasing trend towards more frequent detection of
C. trachomatis was observed with increasingly higher scores for intensity ( $P=0.04)$ involving maternal inflammation only, and for progression $(P=0.009)$ and intensity $(P=0.007)$ of inflammation involving both maternal and fetal tissues.

\section{Discussion}

Chlamydia trachomatis DNA was detected in a high proportion $(25 \%)$ of placentas from women who had early preterm delivery ( $\leq 32$ weeks) and was associated with histopathological signs of placental inflammation.

The strength of this study is the prospective, observational design during which the placentas and clinical data were obtained, the large number of well-described participants, a high follow-up rate, and the use of nucleic acid amplification technique for the detection of $C$. trachomatis. In order to prevent contamination of samples during the process of cutting, during DNA isolation or during the PCR test itself, precautions were taken. Paraffin blocks were cut in badges on different days by two different people using a similar microtome with single-use disposable blades, and care was taken to clean materials between cases. In addition, the order of cutting was recorded and no clustering was observed in the detection of $C$. trachomatis in the cuts.
Table 3 Risk of Chlamydia trachomatis infection according to progression and intensity of placental tissue inflammation

\# OR compared to placenta with no inflammation, ${ }^{\#} P=0.01$

Mantel-Haenszel trend analysis: $* P=0.09$ ** $P=0.04, * * * P=0.01$

\begin{tabular}{|c|c|c|c|}
\hline Placenta tissue & Total, $n$ & $\begin{array}{l}\text { C. trachomatis } \\
\text { positive, } n(\%)\end{array}$ & OR $(95 \% \mathrm{CI})^{\#}$ \\
\hline No placenta inflammation & 181 & $35(19)$ & 1.0 (reference) \\
\hline Any placenta inflammation ${ }^{\# \#}$ & 123 & $41(33)$ & $2.1(1.2-3.5)$ \\
\hline Maternal inflammation only & 50 & $16(32)$ & $2.0(0.98-4.0)$ \\
\hline \multicolumn{4}{|l|}{ Progression* } \\
\hline Stage 1 & 24 & $8(33)$ & $2.1(0.8-5.3)$ \\
\hline Stage 2 & 20 & $6(30)$ & $1.8(0.6-5.0)$ \\
\hline Stage 3 & 6 & $2(33)$ & $2.1(0.4-11.8)$ \\
\hline \multicolumn{4}{|l|}{ Intensity** } \\
\hline Grade 1 & 43 & $13(30)$ & $1.8(0.9-3.8)$ \\
\hline Grade 2 & 7 & $3(43)$ & $3.1(0.7-14.6)$ \\
\hline Maternal and fetal inflammation & 64 & $22(34)$ & $2.2(1.2-4.1)$ \\
\hline \multicolumn{4}{|l|}{ Progression $* * *$} \\
\hline Stage 1 & 4 & $1(25)$ & $1.4(0.1-13.7)$ \\
\hline Stage 2 & 20 & $6(30)$ & $1.8(0.6-5.0)$ \\
\hline Stage 3 & 40 & $15(38)$ & $2.5(1.2-5.2)$ \\
\hline \multicolumn{4}{|l|}{ Intensity*** } \\
\hline Grade 1 & 25 & $7(28)$ & $1.6(0.6-4.1)$ \\
\hline Grade 2 & 39 & $15(38)$ & $2.6(1.2-5.5)$ \\
\hline
\end{tabular}


In addition, DNA isolation was done on different days by different laboratory technicians in different locations, and pipetting was performed using aerosol-resistant tips. Furthermore, the PCR was done using an internal validation ( $\beta$ globine PCR) for each sample separately, and for each run using a negative control (water) and three positive controls (dilutions of purified Chlamydia). None of the negative controls became positive. Therefore, contamination seems unlikely to have influenced the results of the study.

A limitation of the study is that we did not examine placentas from full term pregnancies. Inclusion of term specimens would have enabled additional assessment of the contribution of $C$. trachomatis infection to placental inflammation and its relation to prematurity. Unfortunately, the chorioamnionitis study was initially not designed as such and retrospectively we were not able to trace term specimens from women in the same region and time period for additional comparisons. Another limitation is that although a large number of women participated in this study, the numbers in each category after stratification are small. Furthermore, residual confounding as a result of co-infection by other pathogens was not tested as part of the study. Indeed, the finding of many cases of placental inflammation in the absence of $C$. trachomatis infection would support the presence of other inflammation-inducing pathogens in this cohort of women. Another limitation was that C. trachomatis testing was done retrospectively and that prospectively no specimens were collected from infants, which made it impossible to study vertical transmission.

The PCR technique has been used previously to detect C. trachomatis in placentas [31-33], but reports focusing on the use of PCR to detect Chlamydia in placentas of early preterm deliveries are very limited and from much smaller cohorts. One case report described a stillborn at 36 weeks of gestation in whose placenta $C$. trachomatis was identified [31]. In a Chinese study 59 specimens of chorionic villi were examined that had been collected from women attending an antenatal clinic for artificial abortion within the first trimester of pregnancy, of which three cases (5\%) were found to be $C$. trachomatis positive [32]. In a Croatian study of women with a miscarriage between four and 19 weeks gestation, $C$. trachomatis was detected in only one of 108 placental tissues examined [33].

A $25 \%$ prevalence of $C$. trachomatis in pregnant women is high. It is much higher than the $C$. trachomatis prevalence $(4 \%)$ found in one of our previous population-based studies among 4,055 pregnant women in the same region and time period, using the same test method on urines instead of placentas, and for whom the referal centre is the hospital in which women and neonates were enrolled for the present study. However, our finding is similar to the prevalence $(18 \%)$ found in the women of the latter study who delivered at 32 weeks gestation or less [34]. The difference between these studies may be due to the fact that the current study is hospital based instead of population based, and because not all women who delivered prematurely participated in the other study. Although we were not able to directly assess an association between C. trachomatis infection and preterm delivery from the current study, our findings support those found in the previous study.

We found no significant association of $C$. trachomatis infection with clinical signs in women, neither in the total group nor after stratification. This is not surprising since up to $80 \%$ of chlamydial infections in women are known to be asymptomatic. In addition, urogenital symptoms are often non-specific and likely to be regarded as part of the pregnancy instead of disease and not to be reported. However, we did find an association between $C$. trachomatis infection and histopathological signs of placental inflammation. Histologically proven chorioamnionitis is considered the gold standard against which other clinical predictors of inflammation should be measured [2, 35, 36]. Histological evidence of placental inflammation was present in $40 \%$ of the women and significantly more in chlamydia-positive women than in chlamydia-negative women: 54 versus $36 \%$. Virtually all placentas had signs of maternal inflammation whereas only half the time fetal inflammation was present. Only maternal inflammation would be concordant with infection originating from the maternal side. Our findings, therefore, suggest that ascending $C$. trachomatis infection during pregnancy may extend into the placental tissues. Such invasion of placental tissue is likely to produce an inflammatory response that may trigger preterm labor and delivery [37]. Hence, in case of unexplained preterm delivery additional information can be obtained from histopathological examination of placental tissue and from testing for $C$. trachomatis using highly sensitive nucleic acid amplification techniques.

C. trachomatis is transmitted from mother to newborn during passage through an infected birth canal. However, there are several, mostly anecdotal, reports of newborns delivered by caesarean section that were infected with $C$. trachomatis [38-41]. Ascending chlamydial infection in women undergoing caesarean section may be due to PROM, but the possibility of a transmembrane or transplacental route has also been suggested in the pathogenesis of neonatal chlamydial infection [38, 40]. In our study $43 \%$ of chlamydia-positive women gave birth by caesarean section of whom $27 \%$ had PROM. Since collection and testing of specimens from the newborns was not included in the desing of the study, we are unable to confirm the latter hypothesis. Likewise, we cannot ascribe any neonatal respiratory disease, RDS stage I-II, to $C$. trachomatis infection.

The data presented are highly suggestive of C. trachomatis being a component cause of preterm delivery through 
a pathway that involves a transmembrane or transplacental route of transmission for chlamydial infection leading to chorioamnionitis. Further studies regarding the role of C. trachomatis in either pathway leading to preterm delivery are needed.

\section{Conclusion}

C. trachomatis DNA was frequently detected in the placenta of women with early preterm delivery and was associated with signs of inflammation in the placenta.

Acknowledgments The chorioamnionitis study was funded by the Revolving Fund, Erasmus University MC, Rotterdam, the Netherlands. We thank T.J. Schneider, E. Oschatz, F. Jonkers, N. de Graauw and C.J.A.M. Willemsen for their assistance with the data collection and database. Revolvind Fund, Erasmus MC, Rotterdam, The Netherlands.

Open Access This article is distributed under the terms of the Creative Commons Attribution Noncommercial License which permits any noncommercial use, distribution, and reproduction in any medium, provided the original author(s) and source are credited.

\section{References}

1. McCormick MC. The contribution of low birth weight to infant mortality and childhood morbidity. N Engl J Med. 1985;312(2): 82-90.

2. Hillier SL, Martius J, Krohn M, Kiviat N, Holmes KK, Eschenbach DA. A case-control study of chorioamnionic infection and histologic chorioamnionitis in prematurity. $\mathrm{N}$ Engl $\mathrm{J}$ Med. 1988;319(15):972-8.

3. Lettieri L, Vintzileos AM, Rodis JF, Albini SM, Salafia CM. Does "idiopathic" preterm labor resulting in preterm birth exist? Am J Obstet Gynecol. 1993;168(5):1480-5.

4. Salafia CM, Vogel CA, Vintzileos AM, Bantham KF, Pezzullo J, Silberman L. Placental pathologic findings in preterm birth. Am J Obstet Gynecol. 1991;165(4 Pt 1):934-8.

5. Watterberg KL, Demers LM, Scott SM, Murphy S. Chorioamnionitis and early lung inflammation in infants in whom bronchopulmonary dysplasia develops. Pediatrics. 1996;97(2):210-5.

6. De Felice C, Toti P, Laurini RN, Stumpo M, Picciolini E, Todros $\mathrm{T}$, et al. Early neonatal brain injury in histologic chorioamnionitis. J Pediatr. 2001;138(1):101-4.

7. Mehta R, Nanjundaswamy S, Shen-Schwarz S, Petrova A. Neonatal morbidity and placental pathology. Indian $\mathrm{J}$ Pediatr. 2006;73(1):25-8

8. Hagberg H, Wennerholm UB, Savman K. Sequelae of chorioamnionitis. Curr Opin Infect Dis. 2002;15(3):301-6.

9. Laar MJW van de, Ossewaarde JM. Sexually transmitted diseases in the Netherlands; update 1996 (in Dutch) Bilthoven: RIVM; report no.: 441500006, 1997.

10. Martin DH, Koutsky L, Eschenbach DA, Daling JR, Alexander ER, Benedetti JK, et al. Prematurity and perinatal mortality in pregnancies complicated by maternal Chlamydia trachomatis infections. JAMA. 1982;247(11):1585-8.

11. Harrison HR, Alexander ER, Weinstein L, Lewis M, Nash M, Sim DA. Cervical Chlamydia trachomatis and mycoplasmal infections in pregnancy. Epidemiology and outcomes. JAMA. 1983;250(13):1721-7.

12. Gravett MG, Nelson HP, DeRouen T, Critchlow C, Eschenbach DA, Holmes KK. Independent associations of bacterial vaginosis and Chlamydia trachomatis infection with adverse pregnancy outcome. JAMA. 1986;256(14):1899-903.

13. Sweet RL, Landers DV, Walker C, Schachter J. Chlamydia trachomatis infection and pregnancy outcome. Am J Obstet Gynecol. 1987;156(4):824-33.

14. Martius J, Krohn MA, Hillier SL, Stamm WE, Holmes KK, Eschenbach DA. Relationships of vaginal Lactobacillus species, cervical Chlamydia trachomatis, and bacterial vaginosis to preterm birth. Obstet Gynecol. 1988;71(1):89-95.

15. Association of Chlamydia trachomatis and Mycoplasma hominis with intrauterine growth retardation and preterm delivery. The John Hopkins Study of Cervicitis and Adverse Pregnancy Outcome. Am J Epidemiol. 1989;129(6):1247-57.

16. Ngassa PC, Egbe JA. Maternal genital Chlamydia trachomatis infection and the risk of preterm labor. Int $\mathrm{J}$ Gynaecol Obstet. 1994;47(3):241-6.

17. Claman P, Toye B, Peeling RW, Jessamine P, Belcher J. Serologic evidence of Chlamydia trachomatis infection and risk of preterm birth. CMAJ. 1995;153(3):259-62.

18. Gencay M, Koskiniemi M, Ammala P, Fellman V, Narvanen A, Wahlstrom $\mathrm{T}$, et al. Chlamydia trachomatis seropositivity is associated both with stillbirth and preterm delivery. APMIS. 2000;108(9):584-8.

19. Andrews WW, Goldenberg RL, Mercer B, Iams J, Meis P, Moawad A, et al. The Preterm Prediction Study: association of second-trimester genitourinary chlamydia infection with subsequent spontaneous preterm birth. Am J Obstet Gynecol. 2000;183(3):662-8.

20. Karinen L, Pouta A, Bloigu A, Koskela P, Paldanius M, Leinonen $\mathrm{M}$, et al. Serum C-reactive protein and Chlamydia trachomatis antibodies in preterm delivery. Obstet Gynecol. 2005;106(1): $73-80$.

21. Odendaal HJ, Schoeman J. The association between Chlamydia trachomatis genital infection and spontaneous preterm labour. South Afr J Obstet Gynaecol. 2006;12(3):146-9.

22. Blas MM, Canchihuaman FA, Alva IE, Hawes SE. Pregnancy outcomes in women infected with Chlamydia trachomatis: a population-based cohort study in Washington State. Sex Transm Infect. 2007;83(4):314-8.

23. Kataoka S, Yamada T, Chou K, Nishida R, Morikawa M, Minami $\mathrm{M}$, et al. Association between preterm birth and vaginal colonization by mycoplasmas in early pregnancy. J Clin Microbiol. 2006;44(1):51-5.

24. Silveira MF, Ghanem KG, Erbelding EJ, Burke AE, Johnson HL, Singh RH, et al. Chlamydia trachomatis infection during pregnancy and the risk of preterm birth: a case-control study. Int $\mathbf{J}$ STD AIDS. 2009;20(7):465-9.

25. Brown MA, Lindheimer MD, de Swiet M, Van Assche A, Moutquin JM. The classification and diagnosis of the hypertensive disorders of pregnancy: statement from the International Society for the Study of Hypertension in Pregnancy (ISSHP). Hypertens Pregnancy. 2001;20(1):IX-XIV.

26. Giedion A, Haefliger H, Dangel P. Acute pulmonary X-ray changes in hyaline membrane disease treated with artificial ventilation and positive end-expiratory pressure (PEP). Pediatr Radiol. 1973;1(3):145-52.

27. Volpe JJ. Hypoxic-ischemic encephalopathy: clinical aspects. In: Volpe JJ, ed Neurology of the newborn Philadelphia: Saunders; 2001:331-94. 2001.

28. Bell MJ, Ternberg JL, Feigin RD, Keating JP, Marshall R, Barton L, et al. Neonatal necrotizing enterocolitis. Therapeutic decisions based upon clinical staging. Ann Surg. 1978;187(1):1-7. 
29. Redline RW, Faye-Petersen O, Heller D, Qureshi F, Savell V, Vogler C. Amniotic infection syndrome: nosology and reproducibility of placental reaction patterns. Pediatr Dev Pathol. 2003;6(5):435-48.

30. Lan J, Ossewaarde JM, Walboomers JM, Meijer CJ, van den Brule AJ. Improved PCR sensitivity for direct genotyping of Chlamydia trachomatis serovars by using a nested PCR. J Clin Microbiol. 1994;32(2):528-30.

31. Gencay M, Puolakkainen M, Wahlstrom T, Ammala P, Mannonen L, Vaheri A, et al. Chlamydia trachomatis detected in human placenta. J Clin Pathol. 1997;50(10):852-5.

32. Dong ZW, Li Y, Zhang LY, Liu RM. Detection of Chlamydia trachomatis intrauterine infection using polymerase chain reaction on chorionic villi. Int J Gynaecol Obstet. 1998;61(1):29-32.

33. Matovina M, Husnjak K, Milutin N, Ciglar S, Grce M. Possible role of bacterial and viral infections in miscarriages. Fertil Steril. 2004;81(3):662-9.

34. Rours GIJG. Chlamydia trachomatis infections during pregnancy: consequences for pregnancy outcome and infants. Medical Science [thesis]. Rotterdam: Erasmus University; 2010; 87-104.

35. Pankuch GA, Appelbaum PC, Lorenz RP, Botti JJ, Schachter J, Naeye RL. Placental microbiology and histology and the pathogenesis of chorioamnionitis. Obstet Gynecol. 1984;64(6):802-6.
36. Romero R, Salafia CM, Athanassiadis AP, Hanaoka S, Mazor M, Sepulveda $\mathrm{W}$, et al. The relationship between acute inflammatory lesions of the preterm placenta and amniotic fluid microbiology. Am J Obstet Gynecol. 1992;166(5):1382-8.

37. Goldenberg RL, Hauth JC, Andrews WW. Intrauterine infection and preterm delivery. N Engl J Med. 2000;342(20):1500-7.

38. Shariat H, Young M, Abedin M. An interesting case presentation: a possible new route for perinatal acquisition of Chlamydia. J Perinatol. 1992;12(3):300-2.

39. Bell TA. Chlamydia trachomatis infection in dizygotic twins delivered by caesarean section. Genitourin Med. 1988;64(5): 347-8.

40. La Scolea LJ Jr, Paroski JS, Burzynski L, Faden HS. Chlamydia trachomatis infection in infants delivered by cesarean section. Clin Pediatr (Phila). 1984;23(2):118-20.

41. Givner LB, Rennels MB, Woodward CL, Huang SW. Chlamydia trachomatis infection in infant delivered by cesarean section. Pediatrics. 1981;68(3):420-1. 